\title{
Preface to an ethics of education as a practice in its own right
}

\author{
Pádraig Hogan* \\ Department of Education, National University of Ireland, Maynooth, Ireland
}

\begin{abstract}
Education as a practice in its own right (or sui generis practice) invokes quite a different set of ethical considerations than does education understood as a subordinate activity - i.e. prescribed and controlled in its essentials by the current powers-that-be in a society. But the idea of education as a vehicle for the 'values' of a particular group or party is so commonplace, from history's legacy as well as from ongoing waves of educational reforms, as to appear a quite natural one. So much is this case that the idea of education as a sui generis practice may seem a bit eccentric at first sight. Some preliminary work is called for then to render intelligible the claim that education is indeed a practice in its own right, and to illustrate the original starting point this gives for an exploration of educational ethics. In undertaking this preliminary work, central themes from two major sources are explored and reviewed: Richard Peters' wellknown study Ethics and education and MacIntyre's After virtue. The suggestive merits of both works for advancing a sui generis understanding of education and its conduct are identified. But crucial occlusions are also highlighted in the arguments of both authors, the recognition of which might have enabled their thinking on educational matters to venture onto a different plane. The kind of thinking that emerges from these investigations as most promising for educational ethics is seen to differ in its key features from what the various branches of academic philosophy have to offer by way of ethical theory.
\end{abstract}

Keywords: sui generis practice; inherent purposes; justification; practitioner; universality

\section{Introduction}

Richard Peters' major work Ethics and education, published in 1966, counts as a landmark in the historical development of the philosophy of education as a field of study. It has stood the test of time less well, however, than other landmark studies in the field, such as Dewey's Democracy and education (Dewey 1916/1997), his Experience and education (Dewey 1938/1997), or Freire's (1972) more politically overt Pedagogy of the oppressed. While works like Dewey and Freire's continue to provoke fresh research efforts and inform critical educational initiatives, Peters' study seems to have lost most of the influence it enjoyed in the years following its initial publication. ${ }^{1}$ This is regrettable, not least because the arena of educational

\footnotetext{
*Email: padraig.hogan@nuim.ie
} 
ethics is populated by a more disparate range of stances now - even a bewildering range of 'incommensurable' positions - than in the 1960s and 1970s. It is regrettable also because some of the pathways of thought opened up by Peters, not least his emphasis on universality in educational ethics, deserved to be more influential than they turned out to be.

Among these many pathways, I want to highlight three related ones that should remain central to any adequate consideration of ethics in education. The first of these is Peters' effort to demarcate a concept of education, not by reference to the 'particular values' of one or other individual or group, but by reference to public criteria of justification. The second is his emphasis on education as an initiation into 'worthwhile activities' and morally defensible forms of enquiry and experience. The third is the attempt to provide a universalist basis for educational ethics in democratic societies.

I am keen to argue that these three aspects of Peters' thinking provide key ingredients for a coherent and defensible ethics of education amid the most pluralist of circumstances. But I also hasten to add that this prospect can be realised only if these ingredients are explored in connection with an understanding of education as a practice in its own right. The 'preface' mentioned in the title indicates a threefold task, and an introductory historical reflection that places these tasks in a clear context. The first of the three tasks is to highlight the merits of Peters' efforts to identify public criteria of justification, distinguishing educational actions from those springing from particular interest groups, or from the powers of the currently stronger party. The second task is to reveal how Peters' strong commitment to an academic conception of philosophy covers up again the fresh understanding of educational ethics that his enquiry had begun to unveil. The third task is to move beyond this occlusion in Peters' work: to trace in outline the kind of enquiry called for if an incisive and robust understanding of educational ethics is to be brought to light. Such an enquiry - the heart of which lies beyond any prefatory exercise begins with an elucidation of education as a coherent practice in its own right. It seeks to yield insights that might not only transform philosophical thinking on educational ethics, but are themselves robust candidates for the commitments and practices of practitioners.

The introductory reflection - which follows now in the first section of this article is concerned mainly with revealing the kind of taken-for-granted notions that keep such insights largely invisible in customary thought and action in education. To fail to appreciate the power of such unforced inheritances - that history 'has us' in more far-reaching ways than 'we have it' - is to become delivered over to the most illusory forms of self-assurance: a 'bewitchment' occasioned by our immersion in the familiar. Such an appreciation is of particular consequence where a philosophical understanding of educational practice and its conduct is concerned.

\section{Ethics and education: an inherited 'natural order'}

The notion that education is essentially an undertaking to be controlled by some superior powers or authorities is so widespread that it may seem part of the natural order of things. And this hierarchical notion makes the contrasting notion of education as a practice with its own inherent integrity and coherence seem a curious 
or even an eccentric one. Though discernable in the middle writings of Plato, and in Aristotle's Politics, a hierarchical conception of education as a major cultural force came to prevail in Western civilisation only from the rise of the Roman Empire. ${ }^{2}$ For many centuries thereafter, a politically powerful church came to define education largely in terms of its own doctrines and interests. ${ }^{3}$ But not all hierarchical conceptions of education were, or are, religious. Wars between church and state over the control of schooling in the nineteenth century brought about in many Western countries a dramatic weakening of a centuries-old dominion. But in few cases were the reins passed to educational practitioners and their leaders. Depending on the political and ideological complexion of the country in question, ascendant powers sought to cultivate through schooling fresh allegiances to a range of newly prominent 'isms'. These included nationalism, patriotism, utilitarianism and liberalism, among others.

One might expect that the critical energies of the Enlightenment would have accomplished an overthrow of a hierarchical order in education, or at least the beginnings of its decline. Here, we can cite in particular the efforts of figures like Rousseau (1712-1778) and Kant (1724-1804). Rousseau's (1762/1993) declarations against 'civilised' education in his Émile offer the boldest challenges to the existing educational order: 'Our wisdom is slavish prejudice, our customs consist in control, constraint, compulsion' (10); 'Children's lies are entirely the work of their teachers' (66). And the opening sentences of Kant's noted essay of 1784, 'What is Enlightenment?', sound a note scarcely less bold, if also more circumspect:

Enlightenment is man's emergence from his self-imposed immaturity. Immaturity is the inability to use one's understanding without guidance from another. This immaturity is self-imposed when its cause lies not in lack of understanding, but in lack of resolve and courage to use it without guidance from another. Sapere Aude! [dare to know] 'Have courage to use your own understanding!' - that is the motto of enlightenment. (Kant 1784)

Yet despite such bold aspirations, the educational consequences of the Enlightenment were notably less momentous than were its consequences for politics, law, commerce and the organisation of industrial production. It is of course true that Enlightenment thinking featured strongly in Wilhelm von Humboldt's educational reforms in early nineteenth century Prussia, especially in the founding of the University of Berlin. Elements of Enlightenment thinking can also be found in the educational writings of Pestalozzi (1746-1827) and Froebel (1782-1852). Yet the strongest consequence of the Enlightenment for educational practice was not the growth of new movements of learner-centred pedagogy or self-directing universities. Rather, it was the progressive exchange of an ecclesiastical corps of superiors for more secular kinds of superiors. Hopes that education might achieve recognition as a distinct practice, with its own unique part to play in emergent democratic societies, had to await the early twentieth century, when Dewey's works achieved a period of considerable influence in America and beyond. Even then, new developments did not progress smoothly. The renewed attribution of libertarian motives to Dewey's work by conservative voices brought periodic trouble to his efforts as well as bringing recurring constraints on his intellectual legacy.

The twentieth century witnessed further waves of conflict over the control and direction of educational practice, as the powers of new regimes became consolidated. 
In Eastern Bloc countries, the dominant purposes schools were required to serve were those of Soviet-style communism. In the democracies of the Western world, battles were fought by different interest groups over the control of educational systems as well as over the curriculum to be pursued and the teaching approaches to be practised. In some Western countries, a notable devolution of powers to schools themselves occurred during the late 1960s and 1970s. But this was followed, from the late 1980s onwards, by a dramatic reversal. Successive waves of reform enabled the assumption by governments of very extensive powers over the conduct of education. Despite the fact that these reforms invariably sprang from democratically elected governments, they were scarcely less demanding of compliance than were the ecclesiastical controls on learning in the Middle Ages. The new reforms moreover had two marked features in common with their medieval antecedents. First, they accentuated the hierarchical distinction between the work to be done by educational practitioners and the powers to be exercised by their approved superiors; approval being now conferred by political rather than ecclesiastical authorities. Second, they revealed a deep allegiance on the part of those authorities to doctrines that were inhospitable to criticism or questioning.

A particularly significant feature shared by hierarchical outlooks in education is the privileging of external rather than inherent sources for the ethical orientation of educational action. Characteristically, such sources include political ideologies, religious doctrines, or currently dominant economic and commercial priorities. This picture is familiar, in more authoritarian or benign forms, from the history of education, indeed down to the present. At the more authoritarian end of the spectrum are striking examples like the extensive censorship of scholarship in medieval centres of learning. A more recent - and more violent - example is the educational policy of the Taliban government in Afghanistan during the 1990s. Notable examples from the more benign end include the educational legacies of figures like John Henry Newman (1801-1890) and Matthew Arnold (1822-1888). Notwithstanding the urbane tone of Newman's (1852/1976) classic The idea of a university, he still insisted on 'the dogmatic principle' in his stance on education: 'Christianity, and nothing short of it, must be made the element and principle of all education .... Knowledge of all kinds must minister to Revealed Truth'. ${ }^{4}$ Arnold, for his part, sought to win support for the idea of a culture of 'perfection', through his advocacy of a national system of education modelled on the cultural values and standards of the Anglican church. Examples from the recent waves of educational reform embody a more secular credo, availing now of mercenary devices to recast the ethical orientations of everyday teaching and learning.

In the case of these and other examples of hierarchical conceptions of education, educational practice must minister, to use Newman's telling word, to the demands of superiors with decisive powers to enforce what they lay down. As suggested above, this picture is so familiar as to be widely seen as part of the natural order of things in education. What is less familiar however is that this 'natural order' also means that the ethical significance of education itself is effectively obscured. More precisely, it means that no credence is given to the possibility that education might be a form of life capable of furnishing ethical orientations of its own. By contrast, to highlight just such a possibility is not to say that religious, political, commercial or other influences would be disregarded. Rather, it is to suggest that there are practices of teaching and 
learning that are educational before they are anything else. It is to point out that such practices engage with religious, political, or other influences on a quite different set of considerations than those that might prevail in a church, or a political arena, or other public forum. In these distinctly educational considerations - to be explored below - lie the inherent ethical orientations of education as a practice. And to suggest that educational practice has such ethical orientations of its own is to maintain that it is a practice in its own right. This remains the case moreover, though in somewhat different ways, whether the venue where the practice is being carried out is a 'state school', a 'religious school', an 'independent school', a 'community school' or whatever.

A major philosophical work carrying a title such as Ethics and education might be expected to pursue the articulation and justification of distinct ethical orientations for education, and to provide grounds for distinguishing defensible educational practices from questionable or indefensible ones. Peters' study makes some notable progress in this connection. As already suggested, however, just where his insights approach the kinds of advances which enable thinking to break through onto a new plane, he turns in a different direction. This, as I hope to show later, disappoints the expectations it has quickened. It sacrifices an emergent originality of thought for an embrace of academic conceptions of philosophy that are ill-suited to elucidating the ethics of particular practices, not only education.

In the following section of this preparatory work, I want to investigate more closely both the more promising and less promising furrows to be found in Peters' approach. I hope to make clear the considerable debt the philosophy of education owes to Peters' researches. But I also want to identify shortcomings that point towards the necessity of a different approach, the main outlines of which I will then trace in the final section.

\section{Ethics and education: the significance of R.S. Peters' new departure}

Peters' Ethics and education includes many additional pertinent features to the three I have identified. But as these three are particularly representative of his philosophical approach, they provide a good core of issues for the kind of exploration that can be undertaken within the scope of an essay such as this. Each of the three will be reviewed here in turn: (a) Peters' efforts to demarcate a concept of education linked to public criteria of justification rather than to one or other particular set of values; (b) his characterisation of education as initiation into worthwhile activities; and (c) his elucidation of a universal basis for educational ethics.

\section{(a) The necessity for public criteria of justification}

In relation to this first feature, Peters (1966) calls attention to the philosophical weakness of an educational thinking where "most writers dealing with "the aims of education" persuasively parade the particular values they commend ... but have little to offer by way of justification' (91). In seeking to identify more objective criteria, he argues that the concept of 'education' is inherently normative. It would be a logical contradiction, Peters writes, 'to say that a man was educated but that he had in no way changed for the better' (25). A little later, he refines his description of the 
inherently normative character of education by saying that "education" implies the transmission of what is of ultimate value' (29). If the 'particular values' of individuals or groups are an unsatisfactory source for this ultimate value, the question arises: where can a more satisfactory source, or sources, be found? For Peters, 'arguments derived from a solid foundation in ethical theory' provide the most promising sources (91). This turn to ethical theory for help becomes firstly a survey of the resources supplied by a range of different theories, each of which he finds lacking in some important respects. Peters' critical survey reviews 'naturalism', 'intuitionism' and 'emotivism', before he switches to 'a positive theory of justification', based largely on a modified Kantian, or universalist, approach. The elucidation and application of this more positive theory is the centrepiece of Ethics and education, and we will come back to review key aspects of it in dealing with the second and third features of Peters' approach to be explored here.

Remaining with the first feature, however, Peters' turn to ethical theory makes the explicit claim that 'education raises no philosophical problems that are sui generis' (17). He explains this turn to theory by adding that education 'is a field, like politics, where several of the basic branches of philosophy have application' (19). It is worth noting in passing that Aristotle and countless others might take serious issue with him on this characterisation of politics. But my own concern is to point out, contra Peters, that education is precisely a sui generis undertaking, or more plainly, a coherent practice in its own right. In fact Peters' anticipatory glance towards the 'several branches of philosophy' makes his task more complicated than necessary from the start. Ultimately it puts his enquiry on a less fertile path than would the exploration of the sui generis theme.

Consider for a moment Peters' claim that education raises no philosophical problems that are sui generis. Of course, ethical issues such as justice, care and equality arise in all walks of life. They are not specific to education. But they arise differently in education than in nursing, or social work or clinical psychology. A failure to appreciate this blinds one to what is specific to particular practices. It deepens a rift between practice and theory and almost inevitably cultivates inflated pretensions on the part of the latter. More critically, close attention to the work of educational practitioners shows that Peters' claim is a mistaken one. Teaching, like other practices, engages its practitioners from the beginning in forms of relationships involving ethical judgements that are specific to the practice. These relationships include relationships of imaginative renewal with the subjects being taught; relationships of guided learning with students as individuals and as groups; relationships of professional co-operation with colleagues; relationships of trust and confidence with parents and others. The bulk of the ethical problems that arise for teachers spring from difficulties experienced in establishing and sustaining these relationships. More subtly, they arise from difficulties experienced in understanding these kinds of relationships clearly, or in combining the different kinds of relationships productively and coherently in one's actions as a practitioner. The ultimate origins of the ethical difficulties are likely to lie in shortcomings in understanding, in judgement and in interpersonal capability that constitute key elements of the practitioner's thinking and actions.

For instance, as a teacher I might quite rightly decry the determined resistance of my students as obstructions of my efforts to teach them maths. But I might also fail 
to notice that my own understanding of mathematics - as essentially a matter of mastering procedures and rules - might be a crucial contributory factor. Allied to this might be a failure on my part to appreciate the importance of involving my students in active ways in their own learning. I might also fail to see that this would mean cultivating practices of learning that embody practical forms of justice, and the progressive sharing by my students of more of the responsibility for their learning. Even if I do appreciate this, I might not see the further practical consequences. I might not realise that teaching and learning, far from being essentially a matter of transmission and reception, constitute a joint event, experienced from a range of different perspectives by those involved. I might not notice a necessity to develop new kinds of learning relationships that disclose more imaginatively the topic being studied and that combine this with manifestations of fair play in the learning experiences themselves.

Emphasising the practitioner context as we have just done here calls attention to the way ethical issues are rooted in the nature of the practice, and to the deepening of ethical sensibility required of teachers in the development of their own practice. It highlights the point that practitioners' ethical judgements cannot afford to lose sight of the context of practice itself: of the specific kinds of purposes, relationships and predicaments that constitute that context. And what is said here of education (specifically the deliberate conduct of defensible teaching and learning) can be said in a parallel way of other practices, such as nursing, social work and medicine. That is not to suggest that consulting different branches of philosophy, or different ethical theories, is not important - an ethics of duty, an ethics of justice, an ethics of care, a utilitarian ethics and so on. The fact remains however that many of the inspirations provided by one theory are likely to be in some tension with those provided by another, when 'applied' to the concerns of practice. One of the most frequent examples of this is where considerations of justice conflict, usually in intricate ways, with ones of care, or duty, or compassion in a teacher's work. From the perspective of education as a coherent practice, the weight to be given to any set of considerations relative to others must be informed first by a perceptive command of the particular educational purposes in question. The 'application' of theory may confound as much as it illuminates then, unless the coherence of the practice itself its inherent purposes and benefits - are kept clearly to the fore. Peters is right to emphasise the search for objective criteria. But where an enquiry into the ethics of education is concerned, the focus from the start needs to be on an incisive investigation of education as a distinct and purposeful practice. The most important criteria to be sought, accordingly, are those that identify the sui generis nature of that practice as a coherent and defensible one: as a practice in its own right. Even if that investigation were to conclude that education was not a practice in its own right, the arguments to support such a conclusion would at least have been rendered explicit for scrutiny.

\section{(b) Initiation into worthwhile activities}

The second feature of Peters' approach to be considered is his characterisation of education as an initiation into worthwhile activities. Worthwhile activities, he argues, are those that merit a place on a school curriculum. For Peters they include pursuits, 
such as poetry, science, history, art, carpentry, literature and philosophy. And they exclude other pursuits, such as 'bingo, bridge and billiards', and games more generally. His first kind of justification of this distinction is a 'transcendental' one, in the Kantian sense of the term. In other words, he insists that some distinction of this kind is a necessary presupposition to any informed exercise of choice; to any serious attempt to answer the question 'What ought I to do?', or 'Why do this rather than that?' (153-154). A further kind of justification of the 'worthwhile activities' idea is closely related in Peters' arguments to the role of education in cultivating higherorder qualities of thought and judgement. In the earlier pages of the book, he uses the term 'cognitive perspective' to refer to these (31). In Chapter 5, he refines this further, and stresses the importance for the learner of systematic development of 'conceptual schemes and forms of appraisal which transform everything else that he does' (160). Crucial to his argument here is that students learn to value such conceptual schemes, even if their own initiation into them is sometimes difficult or even boring. The student, in other words, learns to cultivate not only a proficiency in the 'forms of thought in question', but also a 'serious concern or passion for the point of the activity' (165). In two passing remarks a few pages apart, Peters associates this kind of 'concern or passion' with the conviction of Socrates that 'the unexamined life is not worth living' $(163,165)$. He does not, however, develop these references into a further line of justification for education as an initiation into worthwhile activities.

A notable feature of Peters' case in elucidating and justifying worthwhile activities is the restriction of his arguments to the kinds of procedures he identifies with analytic philosophy. In the book's Introduction, he describes these procedures as 'the disciplined demarcation of concepts, the patient explication of the grounds of knowledge and of the presuppositions of different forms of discourse' (15). Yet, his 'worthwhile activities' argument carries in the background some strong resonances of another kind of philosophy, one that breaks through explicitly in the final chapter of Ethics and education. There, Peters invokes the thought of Michael Oakeshott and acknowledges that the 'application' of ethical principles requires more than formal analytic procedures: that it can be accomplished effectively only where people are brought up in an appropriate 'tradition of behaviour' (302). Had Peters pressed this line of exploration further in the book as a whole, Ethics and education would be a different book. Most importantly, it would be difficult for him to avoid a further acknowledgement. This is the recognition that the exploration of an ethics of education, or of medicine, or indeed of politics, can pursue its analytic procedures not independently of tradition, but only within tradition. This insight, however disconcerting initially, opens up some fertile and self-critical possibilities; but ones which a strong adherence to one or other way of doing philosophy tends to becloud - e.g. to analytic philosophy, 'Continental' philosophy, pragmatism, Thomism, etc.

Where education as initiation into worthwhile activities is concerned, pursuing such possibilities might grant a more central and more vibrant place than Peters' approach allows to figures like Oakeshott, Socrates and others who feature periodically in the margins of his arguments. This can be explored further in the final part of the essay, but for now let us take up the third feature of Peters' approach. 


\section{(c) A universal basis for educational ethics}

Peters' efforts to provide a universal basis for educational ethics seeks its warrant by identifying the presuppositions and conditions of possibility of forms of argumentation that can claim universal validity on logical grounds. The application of this semi-Kantian approach to a range of concepts central to education constitutes the heart of Peters' own 'positive theory of justification'. The concepts he identifies as key principles include justice, equality, consideration of the interests of others, freedom and respect for persons.

The merits and limitations of this approach can be illustrated by examining how it works in relation to Peters' key principles. In relation to justice, for instance, Peters writes: 'the principle of justice is a presupposition of any attempt to justify conduct, or to ask seriously the question "What Ought I to do?" (124). This formal kind of argument underscores the significance of the principle of justice for any actions that claim defensibility. But it does not deal with the predispositions, which influence the actual notions of justice in people's minds and hearts. It has little to say to the difficulties that arise where there are conflicting convictions, sincerely held by fellow practitioners of any practice, about this very question of what ought to be done. In relation to equality, Peters argues that the usual way of seeking to justify the concept, namely asking for reasons for treating people alike, puts things the wrong way round. He suggests that it is treating people differently that should require justification, and offers the following principle: 'no one shall be presumed, in advance of particular cases being considered, to have claim to better treatment than another' (121). The grounds for putting things this way, Peters claims, lie in the stance that 'the general principle of no distinctions without differences is a presupposition of practical discourse, or that it is presupposed in any attempt to determine what ought to be done' (121). One could, however, believe oneself to hold faithfully to this principle in theory, while insisting that daily instances of one's work as a practitioner dictate a contrary course of action. For instance, as a school principal I might call attention to pertinent differences - of ability, of aptitude, of linguistic capability among students - that necessitate decisive forms of segregation or discrimination in my school's practices. In defence of my actions, I might call on my long experience, or on long-established custom and practice, which dictates that the differences in question require action that might seem discriminatory at first sight.

Peters' grounds for justification are similar for the other principles. In relation to consideration of interests, he states: "consideration of the interests of others is a presupposition of asking the question "Why do this rather than that?"' (171). In relation to freedom, he offers: 'For the principle of liberty... is also surely a general presupposition of this form of discourse into which any rational being is initiated when he laboriously learns to reason' (181). And in relation to respect for persons he suggests: 'The procedure must therefore be to return to the situation of practical reason and to show that respect for persons is a presupposition that any participant in such a situation must accept' (213).

That Peters himself is already aware of at least some of the limitations of this kind of justification is evident from a comment he makes shortly before presenting the main body of his own positive theory. There, he writes: 'There is no rule for determining which reasons are most relevant when the reasons fall under different 
fundamental principles, which conflict in a particular case. Judgement is required, not a slide rule' (128). The crucial point here however is that the kind of help required from an ethics of education is, first and foremost, insight into the nature and exercise of this very judgement. In the absence of such insight, what distinguishes judgement from pre-judgement, or from one's own unacknowledged preconceptions or prejudices? In fact, Peters' own investigation of the justification of his ethical principles, and of the job to be done by each of them, serves to disclose the precise limitations of the philosophical approach he has been employing. But just at the point where such disclosure brings his enquiry to the threshold of a different arena, Peters seems blind to where the enquiry is being beckoned. He offers instead an almost homely piece of advice about the necessity for good judgement. More crucially, he neglects to acknowledge that judgement and its exercise are invariably predisposed by the hidden hand of history and its influence within human experience.

\section{Education as a distinctive practice}

Each particular practice makes it own ethical demands, or more accurately, its own range of demands. In medicine for instance, that range includes the diversity of issues arising for a GP and the more specific but also more intricate issues faced by a specialist in oncology, cardiology or gynaecology. Nursing has its own range of ethical demands, sharing in some respects those of medicine; but it also has demands particular to its own practice that are recognisably different from those of medicine. Similarly, in education, the ethical demands faced by practitioners in the infant school differ in important respects from those faced by their colleagues in a secondary school, or in a university graduate school. Practitioners in one school moreover may be confronted with more numerous and more challenging ethical issues than their colleagues in a school located a few kilometres away in a different kind of neighbourhood. Even within the same school, the kinds of issues arising within one classroom might be more challenging from those arising in another.

These observations highlight two important points, both of which are promising as research themes. First, it is by investigating the inherent purposes pursued by each practice that the nature and scope of the ethical demands in question become explicit. Second, the practice must be studied not only in relation to its purposes, but also in relation to its actual conduct (its pursuit of these purposes), if the kinds of ethical issues that arise are to be properly understood. It is this latter aspect of the investigation that reveals how, and to what extent, different ethical principles might conflict in the conduct of a particular practice. Clarity about the inherent purposes of the practice is crucial, however, as this provides the light in which conflicting principles might be weighed. In the absence of this clarity, the light shed by ethical theory may at best disclose alternative courses of action: an ethics of duty recommends one course, an ethics of care another, and so on. But, as Peters' comment about 'judgement' recognises (but does not pursue), the capability needed to weigh the alternatives and to decide wisely cannot come from ethical theory as he describes it.

It is difficult to see how Peters' researches could avoid following such promising lines of investigation, had he taken the further step of identifying education as a 
practice in its own right, or even as a candidate for such a description. This step would mean, firstly, that the 'disciplined demarcation' of the concept of 'practice' itself would feature centrally in Ethics and education, alongside Peters' analysis of concepts, such as 'equality', 'freedom', 'justice' and others. Secondly, the chief ethical features of education as a human undertaking might then be reviewed in the light of this analysis. The failure to take this further step however renders Peters' investigations in Ethics and education curiously inconclusive, especially where insights that might inform the defensible conduct of educational practice are concerned.

Two and a half decades after the publication of Ethics and education, the demarcation of the notion of practice was pursued as an exploratory theme by MacIntyre (1981) in his book After virtue. MacIntyre's characterisation of a practice in that book is a complex one, so it is necessary to quote it in full. He identifies a practice as:

any coherent and complex form of socially established co-operative human activity through which goods internal to that form of activity are realized in the course of trying to achieve those standards of excellence which are appropriate to, and partially definitive of, that form of activity, with the result that human powers to achieve excellence, and human conceptions of the ends and goods involved, are systematically extended. (187)

Breaking down this intricate piece of prose, six elements can be identified in MacIntyre's characterisation: (1) a practice is a socially established, co-operative activity that is both coherent and complex; (2) it has its own internal goods; (3) these goods are realised through the work of practitioners who pursue standards of excellence arising from recognition of the goods; (4) the achievement and advancement of these standards help to define the practice itself; (5) human powers to achieve such standards are cultivated by the practice; and (6) such cultivation also contributes to a richer understanding of the practice. MacIntyre devotes a number of pages to elaborating these elements. Further distinctive features of practices and their conduct are made explicit in that elaboration. These include: that every practice has a history of one kind or another; that every practice establishes relationships influenced by the standards its participants pursue; that in order to advance the internal goods of the practice, these relationships require the exercise of certain virtues, such as courage, truthfulness and trust; that practices require institutions to sustain them; that practices can become pursued for external rewards as well as for their internal goods; that to participate properly in a practice is to recognise its internal goods and the standards necessary to achieve these goods (188).

The features identified by MacIntyre help to distinguish practices from human activities that would not count as practices. He gives some examples himself: planting turnips is not a practice but farming is; bricklaying is not a practice but architecture is; and throwing a football skilfully is not a practice, but the game of football is. Other examples of practices he includes are fields of study, such as physics, chemistry and biology, and artistic pursuits, such as music and painting (187).

MacIntyre's analysis of practice explores central aspects of the landscape from which Peters' Ethics and education turned aside. In doing so, it provides a potentially fruitful path for identifying the distinctiveness of education as a practice, and of its 
inherent ethical orientations; or so it would seem. Yet, it is just here that MacIntyre himself turns aside. In a notable interview with Joseph Dunne (MacIntyre and Dunne 2004), who suggested to him the possibilities of the path just mentioned, MacIntyre responded by declaring that 'teaching itself is not a practice, but a set of skills and habits turned to a variety of practices' (5). Initially, one might think that MacIntyre might just have meant: 'teaching is not a practice but education is', like his earlier statements about bricklaying, turnip planting and ball throwing. But MacIntyre goes on to say that 'teaching is never more than a means' and that 'teaching does not have its own goods'. He adds that 'the life of a teacher of mathematics, whose goods are the good of mathematics, is one thing; a life of a teacher of music whose goods are the goods of music is another' (8).

To deal fully with MacIntyre's claims here would take more than a few pages. ${ }^{5}$ The kernel of his claim that teaching is not a practice is contained however in the two statements 'teaching is never more than a means' and 'teaching does not have its own goods'. Yet there is something arcane, even a philosophical aloofness, in MacIntyre's analysis of notion of the 'internal goods' of a practice. Had he explored the notion of 'internal goods' further, by way of a few examples from experience, it would be necessary to acknowledge that such goods can be understood in contrasting ways. ${ }^{6}$ For instance, they can be viewed as already-established accomplishments, to be valued essentially for the self-contained satisfactions they yield to competent participants and spectators (e.g. the 'goods' of chess or of cricket). But 'goods' can also be viewed as valued human goals that have yet to be brought about. Here, they direct attention to purposes that are ever to be clarified and justified, pursued and renewed. Examples here include the promotion of independent living in their own homes for people with chronic illnesses, the search for better diagnosis and treatment of cancers, the cultivation of a range of human dispositions through teaching and learning. It is worth noting in passing that 'internal goods' of the already-established kind and of the goal-oriented kind can themselves become mingled with 'external goods'. In the case of the first kind, one might play cricket not only for its inherent satisfactions, but also for external rewards, such as social status and prestige. In the case of the second, one might pursue a course of studies not only for inherent benefits, such as fluency in a particular subject, or the betterment of one's powers of understanding, analysis and discernment. One could also have an eye to highly paid career opportunities that the course of studies might bring within one's reach.

MacIntyre leaves 'internal goods' of the second (goal-oriented) kind largely unexplored: 'goods' that can more plainly be called the inherent purposes of practices, such as nursing, medicine, social work and education. This neglect, and the related preoccupation with more academic and aesthetic 'goods', diminishes MacIntyre's awareness of practices that are primarily oriented to promoting one or more aspects of human flourishing. ${ }^{7}$ It is as a practice in this latter domain that education can be called a practice in its own right. Accordingly, its inherent purposes are not only subject specific (pursuing the goods of history, the goods of physics and so on). They also include goals that are generic to the developmental nature of practitioners' work: for example, the cultivation of qualities, such as method in enquiry, discernment in analysis, even-handedness in weighing evidence and attentiveness in listening to contrasting perspectives to one's own. The identification of such goals brings to the 
centre of philosophical investigation the communal forms of enquiry that Peters' references to figures like Socrates and Oakeshott touch on more remotely.

The ethical orientations for practitioners that emerge from the inherent purposes of education suggest moreover a range of practical virtues, ones that are associated with the promotion of defensible and promising forms of teaching and learning. Such orientations themselves disclose insights, capabilities and communicative actions that have a primary claim on the commitments of teachers, quite apart from teachers' personal convictions in matters political or religious. In particular cultural settings, however, this point and its significance might be obscured by the inherited legacy of the practice; beclouded, that is, by the institutionalised attitudes and routines that prevail in the conduct of the practice in that cultural setting. Purposes which are those of a particular institution (e.g. a church, a political party, a commercial body) might have become so dominant that they are widely taken to be the inherent purposes of the practice itself, even by the bulk of practitioners. Thus we see how easily the kind of 'natural order' reviewed earlier insinuates itself and extends its realm.

\section{Conclusion}

This 'preface' prepares the way for a more substantial investigation of the ethical orientations of education as a practice in its own right. It identifies some mistakes to be avoided and a number of key points to be borne in mind if such larger investigation is to be profitable; if it is to yield coherent and convincing illuminations for the conduct of teaching and learning. Five such key points can be summarised by way of conclusion. First, this more substantial investigation involves identifying the nature and scope of the inherent purposes of the practice. Second, related to this is the elucidation of a recognisable family of virtues that describe exemplary instances of the practice. Third, this in turn involves an exploration of the kinds of relationships through which these virtues, and their educational fruits, are nourished (as distinct from deformed). Fourth, another important feature of the larger investigation is the disclosure of educationally productive pathways amid the diverse influences that come into play when teaching and learning are experienced, not as a delivery or transmission, but as a joint venture. Finally, but not least, the more substantial investigation involves exploring how educational practice might turn to its advantage the inescapable fact that it is embedded in one or more traditions.

\section{Notes}

1. On this point, see Warnick (2007).

2. From a historical point of view, it would be more accurate to associate the dominant Western conceptions of education less with the actual writings of Plato and Aristotle than with their effective legacy: the neo-Platonism of Augustine and other Latin Church Fathers in the fourth to fifth centuries, and later the neo-Aristotelianism of Thomas Aquinas in thirteenth century. This dominant conception received its most decisive early impetus from the fusion of the Roman Empire's interests with institutionalised forms of Christianity during the reign of Emperor Theodosius I (378-395). The rise of a particular kind of Christian theology, associated with saints Ambrose (338-397), Jerome (347-420), and especially Augustine (354-430), was also central in this event. 
3. See Boyd and King $(1972,99)$.

4. This passage from Newman's third of seven 'Catholicus' letters to The Times newspaper in 1841 is quoted by $\operatorname{Ker}(1998,200)$.

5. A number of essays in MacIntyre and Dunne (2004) review in detail this controversial claim of MacIntyre's.

6. This criticism of MacIntyre's failure to make necessary distinctions in his account of practice is pursued by Miller $(1994,250)$. Important consequences of these failures for how university education is understood and practised are explored by Smith (2004, 74-87).

7. The neglect is partially compensated for in MacIntyre's later book Dependent rational animals (MacIntyre 1999, 77, 89), where he specifically mentions 'the virtues of caring and teaching' that enable any person to become an 'independent practical reasoner'. He also says: 'All teaching requires some degree of care for the student qua student, as well as for the subject matter of the teaching'. His comments in such instances presuppose that teaching has indeed 'its own goods', though MacIntyre does not pursue the implications of this.

\section{References}

Boyd, W., and E.J. King. 1972. The history of western education. London: A\&C Black.

Dewey, J. 1916/1997. Democracy and education. New York: The Free Press.

Dewey, J. 1938/1997. Experience and education. New York: Touchstone.

Freire, P. 1972. Pedagogy of the oppressed. Trans. M. Bergman Ramos. Harmondsworth: Penguin.

Kant, I. 1784. An answer to the question: What is enlightenment? http://www.english.upenn. edu/ mgamer/Etexts/kant.html

Ker, I. 1998. John Henry Newman - A biography. Oxford: Clarendon Press.

MacIntyre, A. 1981. After virtue (Second revised edition 1985). London: Duckworth.

MacIntyre, A. 1999. Dependent rational animals. London: Duckworth.

MacIntyre, A., and J. Dunne. 2004. Alasdair MacIntyre on education: In dialogue with Joseph Dunne. In Education and practice: Upholding the integrity of teaching and learning, eds. J. Dunne and P. Hogan, 1-17. Oxford, Malden: Blackwell Publishers.

Miller, D. 1994. Virtues, practices and justice. In After MacIntyre: Critical perspectives on the work of Alasdair MacIntyre, eds. J. Horton and S. Mendus, 245-64. Oxford, Cambridge: Polity Press, in association with Blackwell Publishers.

Newman, J.H. 1852/1976. The idea of a university. ed. I. Ker (with an Introduction). Oxford: Clarendon Press.

Peters, R.S. 1966. Ethics and education. London: George Allen \& Unwin Ltd.

Rousseau, J.-J. 1762/1993. Émile. Trans. B. Foxley with Introduction by P.D. Jimack. London: JM Dent.

Smith, R. 2004. Thinking with each other: The peculiar practice of the university. In Education and practice: Upholding the integrity of teaching and learning, eds. J. Dunne and P. Hogan, 74-87. Oxford, Malden: Blackwell Publishers.

Warnick, B.R. 2007. Ethics and education forty years later. Educational Theory 57, no. 1: 53-73. 